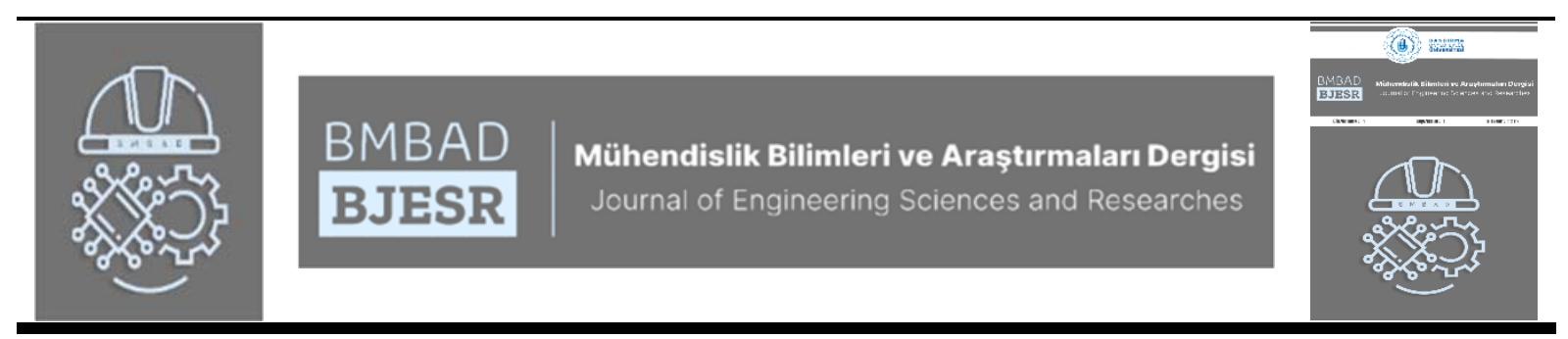

\title{
1-heptanol/benzin karışımlarının kullanıldığı buji ateşlemeli motorun çalışma parametrelerinin Taguchi tasarım metodu ile iyileștirilmesi
}

\section{Improving the operating parameters of the spark ignition engine using 1-heptanol / gasoline mixtures with Taguchi design method}

\author{
${ }^{1}$ Hayri Yaman (D), ${ }^{2}$ Murat Kadir Yeşilyurt (D), ${ }^{3}$ Samet Uslu (D) \\ ${ }^{I}$ Kırıkkale Üniversitesi, Otomotiv Teknolojileri Programı, Kırıkkale, Türkiye \\ ${ }^{2}$ Yozgat Bozok Üniversitesi, Makine Mühendisliği Bölümü, Yozgat, Türkiye \\ ${ }^{3}$ Karabük Üniversitesi, Makine Mühendisliği Bölümü, Karabük, Türkiye

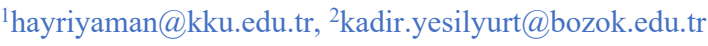 \\ 3sametuslu@karabuk.edu.tr
}

Araştırma Makalesi/Research Article

A R T I C L E I N F O
Article history
Received : 4 March 2021
Accepted : 21 March 2021

Keywords:

1-heptanol, Taguchi design, optimization, performance, spark ignition engine.

A B S T R A C T

In this study, Taguchi design method supported by analysis of variance (ANOVA) was used to determine the optimum values of motor variables corresponding to optimum motor output. For the design, 1-heptanol ratio (HR), compression ratio $(\mathrm{CR})$ and engine load were selected as engine variables, while the resulting brake thermal efficiency (BTE) and brake specific fuel consumption (BSFC) were selected as engine responses. Among the engine variables, three different values were selected as $0 \%, 5 \%$ and $15 \%$ for $\mathrm{HR}$, 6.0:1, 8.0:1 and 10.0:1 for CR, 9, 18 and $27 \mathrm{Nm}$ for load. According to the results, the optimum engine operating parameters required to obtain the best BTE and BSFC values were found to be 5\% HR, 10.0:1 CR and $27 \mathrm{Nm}$ load. BTE and BSFC based on optimum operating parameters were found to be $33.120 \%$ and $0.278 \mathrm{~kg} / \mathrm{kWh}$, respectively. When the results obtained from the optimization and the experimental results were compared, it was revealed that the optimization was successfully performed with an error of less than $10 \%$.

(C) 2020 Bandirma Onyedi Eylul University, Faculty of Engineering and Natural Science. Published by Dergi Park. All rights reserved.

\section{Ö Z E T}

Bu çalışmada, optimum motor çıkışına karşılık gelen motor değişkenlerinin optimum değerlerini saptamak için varyans analizi (ANOVA) destekli Taguchi tasarım metodu kullanılmıştır. Tasarım için 1-heptanol oranı (HO), sıkıştırma oranı (SO) ve motor yükü, motor değişkenleri olarak seçilirken, bu değişkenlere bağlı olarak ortaya çıkan fren efektif verim (FEV) ve fren özgül yakıt tüketimi (FÖYT) motor cevapları olarak seçilmiştir. Motor değişkenlerinden $\mathrm{HO}$ için $\% 0, \% 5$ ve $\% 15$, SO için 6.0:1, 8.0:1 ve 10.0:1, yük için 9, 18 ve $27 \mathrm{Nm}$ olmak üzere üç farklı değer seçilmiştir. Elde edilen sonuçlara göre, en iyi FEV ve FÖYT değerlerinin elde edilmesi için gereken optimum motor çalışma parametreleri $\% 5 \mathrm{HO}, 10.0: 1 \mathrm{SO}$ ve $27 \mathrm{Nm}$ yük olarak bulunmuştur. Optimum çalışma parametrelerine istinaden ortaya çıkan FEV ve FÖYT ise sırasıyla $\% 33.120$ ve $0.278 \mathrm{~kg} / \mathrm{kWh}$ olarak bulunmuştur. Optimizasyondan elde edilen sonuçlar ile deney sonuçları kıyaslandığında ise \%10'dan daha az bir hatayla optimizasyonun başarılı bir şekilde yapıldığı ortaya çıkmıştır.

(C) 2020 Bandırma Onyedi Eylül Üniversitesi, Mühendislik ve Dağa Bilimleri Fakültesi. Dergi Park tarafından yayınlanmaktadır. Tüm Hakları Saklıdır. 


\section{GİRIŞ}

Son zamanlarda tüm dünyada artan teknolojik gelişmeler ve artan nüfusla birlikte aktif araç sayısı aşırı bir şekilde artmış ve buna bağlı olarak artan atmosfer ve çevre kirliğinin yanında, yakıt rezervleri hızla azalmaya başlamıştır [1-5]. Bu sebeplerden dolayı araştırmacılar çevre dostu alternatif yakıt arayışına girmişlerdir [6-9]. Bu amaçla benzinli motorlarda benzine göre daha yüksek oksijen içeriğine sahip olmaları ve temiz yanma sağlaması nedeniyle alkollü yakıtlar yıllardır tercih edilmektedir [10-12]. Son yıllarda metanol, etanol gibi çoğunlukla fermantasyon işlemi ile biokütleden üretilebilen düşük karbonlu alkoller kıvılcım ateşlemeli motorlar için alternatif yakıt katkı maddeleri olarak kullanılmışlardır. Ancak, 1-heptanol'ün de içerisinde bulunduğu yüksek karbonlu alkoller, düşük karbonlu alkollere kıyasla yüksek enerji yoğunlukları ve daha iyi karışım oluşturma kabiliyetleri gibi nedenlerden dolayı son yıllarda daha çok tercih edilmektedir [13-15]. 1-heptanol ve izomerlerinin benzinli motorlarda kullanımına ilişkin literatürde herhangi bir çalışma bulunmamakla birlikte, dizel motorların kullanımı ile ilgili çalışmalar vardır $[14,16,17]$.

Alternatif yakıt arayışında bir yakıtın içten yanmalı motorda kullanımının uygunluğunun belirlenebilmesi için bir dizi deney yapılması gerekmektedir. Bu deneyler maliyetli olmasının yanında oldukça zaman da almaktadır. Bundan dolayı, alternatif yakıt arayışının daha verimli bir şekilde yapılabilmesi için araştırmacılar son yıllarda gelişen teknoloji ile birlikte bilgisayar yazılımlarına ve uygulamalarına yönelmişlerdir. Taguchi bu uygulamalardan biridir. Taguchi tasarımı, seçilen girdi değişkenlerinden hangisinin daha etkili olduğunu ortaya çıkaran ve tüm değişkenlerin optimum seviyelerini belirleme becerisine sahip bir uygulamadır $[18,19]$. Taguchi tasarım metodunun içten yanmalı motorlarda kullanımı ile ilgili literatürde birçok çalışma mevcuttur. Uslu ve Aydin [20] alternatif yakıt olarak dietil eter/palmiye yağı biyodizel/dizel karışımlarını kullandığı tek silindirli dizel motorda optimum karışım oranını ve aynı zamanda optimum püskürtme avansı ve motor yükü seviyeleri belirlemek amacıyla Taguchi yöntemini kullanmışlardır. Üç seviyeli dört faktör olarak seçtikleri deney tasarımı için Taguchi $\mathrm{L}_{27}$ ortogonal dizisini kullanmışlardır. Emisyonlar için genel olarak yüksek dietil eter oranlarının ve düşük palmiye yağı oranlarının en iyi seviyeleri olduğu sonucuna varmışlardır. Performans parametreleri açısından bakıldığında ise düşük dietil eter oranları, düşük püskürtme avansı ve ortalama motor yükü değerlerinde en iyi çıkışlar elde edilmiştir. Sonuç olarak yazarlar Taguchi yönteminin dizel motorun optimizasyonu için başarılı bir şekilde kullanılabileceğini ifade etmişlerdir. Ansari vd. [21] polanga biyodizel/dizel yakıt karışımlarının kullanıldığı dizel motorda giriş parametrelerinin seviyeleri üzerinde analiz yapmak amacıyla Taguchi yöntemini tercih etmiş̧lerdir. Giriş parametreleri olarak biyodizel oranı, püskürtme zamanı ve püskürtme basıncını seçmişlerdir. Performans değerlendirmesine göre 220 bar püskürtme basıncında $\% 30$ polanga biyodizel karışımına sahip motorun çalışma koşullarının dizel ile yakın sonuçlar verdiğini ifade etmişlerdir. Çalışmada elde edilen optimum FEV, hidrokarbon, azot oksitler ve is emisyon değerleri, üst ölü noktadan $15^{\circ}$ önce yakıt püskürtme zamanlaması ve 200 bar püskürtme basıncı ile $\% 30$ polanga biyodizel karışımında sırasıyla $\% 32.59,20.3 \mathrm{ppm}$, $551 \mathrm{ppm}$ ve \%94.2'dir. Sonuçlara dayanarak, polanga biyodizel karışımlarının yukarıda belirtilen çalışma koşullarına göre dizele alternatif olarak direkt enjeksiyonlu dizel motora uygulanabilen önemli bir alternatif olduğunu belirtmişlerdir. Balki vd. [22] saf benzin, etanol ve metanol kullanılan buji ateşlemeli motorda minimum sayıda motor testi ile en iyi motor performansını ve egzoz emisyonlarını elde etmek için optimum çalışma parametrelerini bulmak amacıyla Taguchi yöntemini uygulamışlardır. Bu amaçla, test motoru farklı sıkıştırma oranı, motor devri ve ateşleme zamanlaması altında çalıştırıldı. Sonuca göre tüm yakıtlar için optimum sıkıştırma oranı ve motor devri değeri 9.0:1 ve $2400 \mathrm{~d} / \mathrm{d}$ olarak bulunmuştur. Jena vd. [23] biyodizel / dizel yakıt karışımları ile çalışan dizel motorda motor yükü, $\mathrm{SO}$ ve karışım oranının $\mathrm{BTE}$ ve $\mathrm{NO}_{\mathrm{x}}$ üzerindeki etki derecelerini belirlemek ve optimize etmek için Taguchi yöntemini kullanmışlar ve optimum motor koşullarının \%100 motor yükü, 17.5:1 SO ve \%20 karışım oranı olduğunu tespit etmişlerdir. Rai ve Sahoo [24] alternatif yakıt olarak biyodizel kullandıkları dizel motorda Taguchi ile deney tasarımı yapmışlar ve farklı SO, farklı motor yükleri ve farklı karıştırma oranları ile deneyleri gerçekleştirmişlerdir. 17.0:1 SO değeri, $10 \mathrm{~kg}$ motor yükü ve $\% 30$ karışım oranını optimum değerler olarak belirlemişlerdir.

Yakıt olarak 1-heptanol kullanımına ilişkin önceki çalışmaların detaylı araştırması sonucunda, 1-heptanolün dizel motorlarda kullanımı ile alakalı birçok çalışma olmasına rağmen, buji ateşlemeli motorlarda 1-heptanol kullanımına ilişkin güvenilir çalışmalara rastlanamamıştır. Bu çalışmanın öncelikle buji ateşlemeli motorlar için yeni bir yakıt türünü test etmeyi amaçladığı söylenebilir. Öte yandan gelişen teknoloji ile birlikte yakıt olarak 1heptanol ile yapılan birçok deney yerine birkaç deney yaparak hem zamandan hem de masraftan kaçınmak ve aynı zamanda optimum yakıt yüzdesini ve çalışma koşullarını belirlemek amaçlanmıştır. Bu amaçla, 1-heptanol/benzin karışımları ile çalışan tek silindirli buji ateşlemeli bir motorun optimum motor çıkışına karşılık gelen motor değişkenlerinin optimum değerlerini saptamak için Taguchi tasarım metodu kullanılmıştır.

\section{MATERYAL VE YÖNTEM}

Taguchi tasarımı, çeşitli motor çalışma değişkenlerinin optimizasyonu için dikey sütunlar oluşturarak, mümkün olan en az deneyle optimum motor değişkenlerini ve motor çıkışlarını belirleyebilen ve deney sırasında harcanan zaman ve parayı azaltarak istatistiksel tasarım oluşturan etkili bir araçtır [20]. Ayrıca, Taguchi seçilen 
değişkenlerin yanıtlar üzerindeki etkisinin bir ölçüsünü sağlayan sinyal-gürültü ( $\mathrm{S}$ / N) oranı oluşturur. Daha büyük bir S / N oranı, bu değişken için en iyi seviyeyi göstermektedir [25]. "Daha büyük daha iyidir", "daha küçük daha iyidir" ve "nominal en iyisidir" olmak üzere birkaç S / N oranı vardır. Bu çalışmada, FEV için 'daha büyük daha iyidir' ve FÖYT için 'daha küçük daha iyidir' seçenekleri kullanılmıştır. S/N oranları, aşağıda verilen (1) ve (2) nolu denklemler kullanılarak elde edilmiştir.

'Daha büyük daha iyidir';

$$
S / N=-10 \log _{10}\left[\frac{1}{n} \sum_{i=1}^{n} \frac{1}{y_{i}^{2}}\right]
$$

'Daha küçük daha iyidir';

$$
S / N=-10 \log _{10}\left[\frac{1}{n} \sum_{i=1}^{n} y_{i}^{2}\right]
$$

Burada $n$ test sayısı, $i$ tasarım parametresi sayısı ve $y_{i}$ de her bir test sonucunu ifade etmektedir.

Taguchi tasarım ile yapılan deney tasarımı Tablo 1'de gösterilmektedir. Deney tasarımına göre üç farklı 1-heptanol yüzdesinde (\%0, \%5 ve \%15), üç farklı SO (6.0:1, 8.0:1 ve 10.0:1) değerinde ve üç farklı motor yükünde $(9,18$ ve $27 \mathrm{Nm}$ ) deneyler yapılmıştır. Deneysel çalışmalarda kullanılan yakıtların özellikleri Tablo 2'de verilmiştir. Deneyler tek silindirli, dört zamanlı, SO ayarlanabilir Kirloskar marka benzinli motorda gerçekleştirilmiştir.

\begin{tabular}{|c|c|c|c|}
\hline Deneme & F1 (HO) & F2 (SO) & F3 (Yük) \\
\hline 1 & 1 & 1 & 1 \\
\hline 2 & 1 & 1 & 2 \\
\hline 3 & 1 & 1 & 3 \\
\hline 4 & 1 & 2 & 1 \\
\hline 5 & 1 & 2 & 2 \\
\hline 6 & 1 & 2 & 3 \\
\hline 7 & 1 & 3 & 1 \\
\hline 8 & 1 & 3 & 2 \\
\hline 9 & 1 & 3 & 3 \\
\hline 10 & 2 & 1 & 1 \\
\hline 11 & 2 & 1 & 2 \\
\hline 12 & 2 & 1 & 3 \\
\hline 13 & 2 & 2 & 1 \\
\hline 14 & 2 & 2 & 2 \\
\hline 15 & 2 & 2 & 3 \\
\hline 16 & 2 & 3 & 1 \\
\hline 17 & 2 & 3 & 2 \\
\hline 18 & 2 & 3 & 3 \\
\hline 19 & 3 & 1 & 1 \\
\hline 20 & 3 & 1 & 2 \\
\hline 21 & 3 & 1 & 3 \\
\hline 22 & 3 & 2 & 1 \\
\hline 23 & 3 & 2 & 2 \\
\hline 24 & 3 & 2 & 3 \\
\hline 25 & 3 & 3 & 1 \\
\hline 26 & 3 & 3 & 2 \\
\hline 27 & 3 & 3 & 3 \\
\hline
\end{tabular}

Tablo 1. Üç seviyeli üç değişkenin Taguchi tasarımı 
Tablo 2. Yakıt özellikleri

\begin{tabular}{lcc}
\hline & Benzin & 1-heptanol \\
\hline Kimyasal formül & $\mathrm{C}_{8} \mathrm{H}_{18}-\mathrm{C}_{7} \mathrm{H}_{16}$ & $\mathrm{C}_{7} \mathrm{H}_{16} \mathrm{O}$ \\
Yoğunluk $\left(\mathrm{g} / \mathrm{cm}^{3}\right)$ & $0.720-0.775$ & 0.819 \\
Oksijen içeriği $(\%$ kütlesel $)$ & 0 & 14.13 \\
Alt 1s1l değer $(\mathrm{MJ} / \mathrm{kg})$ & 44.0 & 34.65 \\
$40^{\circ} \mathrm{C}$ 'deki kinematik viskozite $\left(\mathrm{mm}^{2} / \mathrm{s}\right)$ & $0.5-0.6$ & 3.320 \\
\hline
\end{tabular}

\section{BULGULAR VE TARTIŞMA}

Seçilen motor değişkenlerinin orantısal etkisini tanımlamak için ANOVA kullanılmıştır. ANOVA, çeşitli faktör düzeylerinde yanıt faktörü araçlarını karşılaştırarak bir veya daha fazla değişkenin önemini değerlendirir. Bu çalışmada, 1-heptanol/benzin karışımları kullanılarak seçilen motor değişkenlerinin FEV ve FÖYT üzerindeki etkilerini belirlemek için ANOVA uygulanmıştır. FEV ve FÖYT için ANOVA sonuçları Tablo 3'te gösterilmektedir. Bu çalışma \%95 güven derecesinde yapıldığ 1 için bir faktörün cevap üzerinde etkili olduğundan bahsedebilmek için o faktörün p-değerinin 0.05 'ten düşük olması gerekmektedir. Aynı zamanda, F-değerinin de yüksek olması gerekmektedir. ANOVA tablosuna göre, FEV üzerindeki etkiler incelendiğinde, lineer açıdan HO'nun kayda değer bir etkisinin olmadığı, diğer yandan ise SO ve motor yükünün etkili faktörler olduğu söylenebilir. Aynı zamanda, FÖYT üzerindeki durum incelendiğinde FEV için elde edilen sonuçlarla benzer sonuçlarla karşılaşılmaktadır.

Tablo 3. FEV ve FÖYT için ANOVA sonuçları

\begin{tabular}{|c|c|c|c|c|}
\hline & \multicolumn{2}{|c|}{ FEV } & \multicolumn{2}{|c|}{ FÖYT } \\
\hline & F-değeri & p-değeri & F-değeri & p-değeri \\
\hline Model & 7.85 & 0.000 & 53.29 & 0.000 \\
\hline Lineer & 21.74 & 0.000 & 146.92 & 0.000 \\
\hline A- HO & 0.05 & 0.818 & 0.50 & 0.488 \\
\hline B-SO & 15.40 & 0.001 & 55.54 & 0.000 \\
\hline C- Yük & 49.77 & 0.000 & 384.72 & 0.000 \\
\hline Kare & 1.07 & 0.389 & 10.70 & 0.000 \\
\hline $\mathrm{A}^{2}$ & 1.63 & 0.219 & 0.07 & 0.800 \\
\hline $\mathbf{B}^{2}$ & 0.78 & 0.388 & 17.35 & 0.001 \\
\hline $\mathrm{C}^{2}$ & 0.78 & 0.388 & 14.70 & 0.001 \\
\hline Etkileşim & 0.75 & 0.537 & 2.24 & 0.121 \\
\hline$A * B$ & 1.55 & 0.231 & 0.04 & 0.836 \\
\hline$A^{*} \mathbf{C}$ & 0.18 & 0.679 & 2.56 & 0.128 \\
\hline$B * C$ & 0.53 & 0.476 & 4.12 & 0.058 \\
\hline Hata payı & $7.36 \%$ & & $3.27 \%$ & \\
\hline $\mathbf{R}^{2}$ & $93.64 \%$ & & $96.73 \%$ & \\
\hline $\operatorname{Adj} . R^{2}$ & $92.45 \%$ & & $95.00 \%$ & \\
\hline Pred. $\mathbf{R}^{2}$ & $88.22 \%$ & & $91.20 \%$ & \\
\hline
\end{tabular}

Taguchi'den FEV için elde edilen S/N oranları Şekil 1'de gösterilmektedir. Şekle bakıldığında, \%5 heptanol, 10 SO ve 27 Nm motor yükü değerleri en iyi FEV değerinin elde edileceği motor değişkenleri olarak tespit edilmiştir. Şekil 2'de gösterilen Pareto grafiğine göre kırmızı kesikli düşey çizginin sağında oldukları için yük ve SO FEV üzerindeki etkili motor değişkenleri olarak tespit edilmiştir. Ayrıca, FEV için elde edilen regresyon denklemi de denklem (3)’te verilmiştir. SO'nun artan değeri ile birlikte silindir içi sıcaklık ve basıncın arttığı ve dolayısıyla FEV değerinin yükseldiği bilinen bir durumdur. En iyi FEV için SO değerinin maksimum çıkması beklenen bir durum olmuştur. SO'ya benzer bir şekilde artan motor yükü de FEV'in artmasını sağlayan bir değişkendir. Artan motor yükü ile silindir içi sıcaklık ve basınç artar ve FEV artış gösterir. En iyi FEV değerinin en yüksek yük değeri olan 27 Nm'de elde edilmesi de beklenen bir durum olarak karşımıza çıkmıştır. Diğer taraftan, 1-heptanol, içerisinde oksijen ihtiva eden bir yakıt türüdür. Dolayısıyla, artan HO ile birlikte FEV yükselmiştir. Ancak, \%5'ten daha fazla HO değeri ile birlikte FEV tekrar azalma eğilimine girmiştir. 1-heptanolun alt 1sıl değerinin benzine kıyasla düşük olması nedeniyle karışım içerisindeki HO arttıkça karışımın alt 1sıl değerinin çok düşmesinden dolayı FEV'deki bu düşmenin gerçekleştiği düşünülmektedir. 


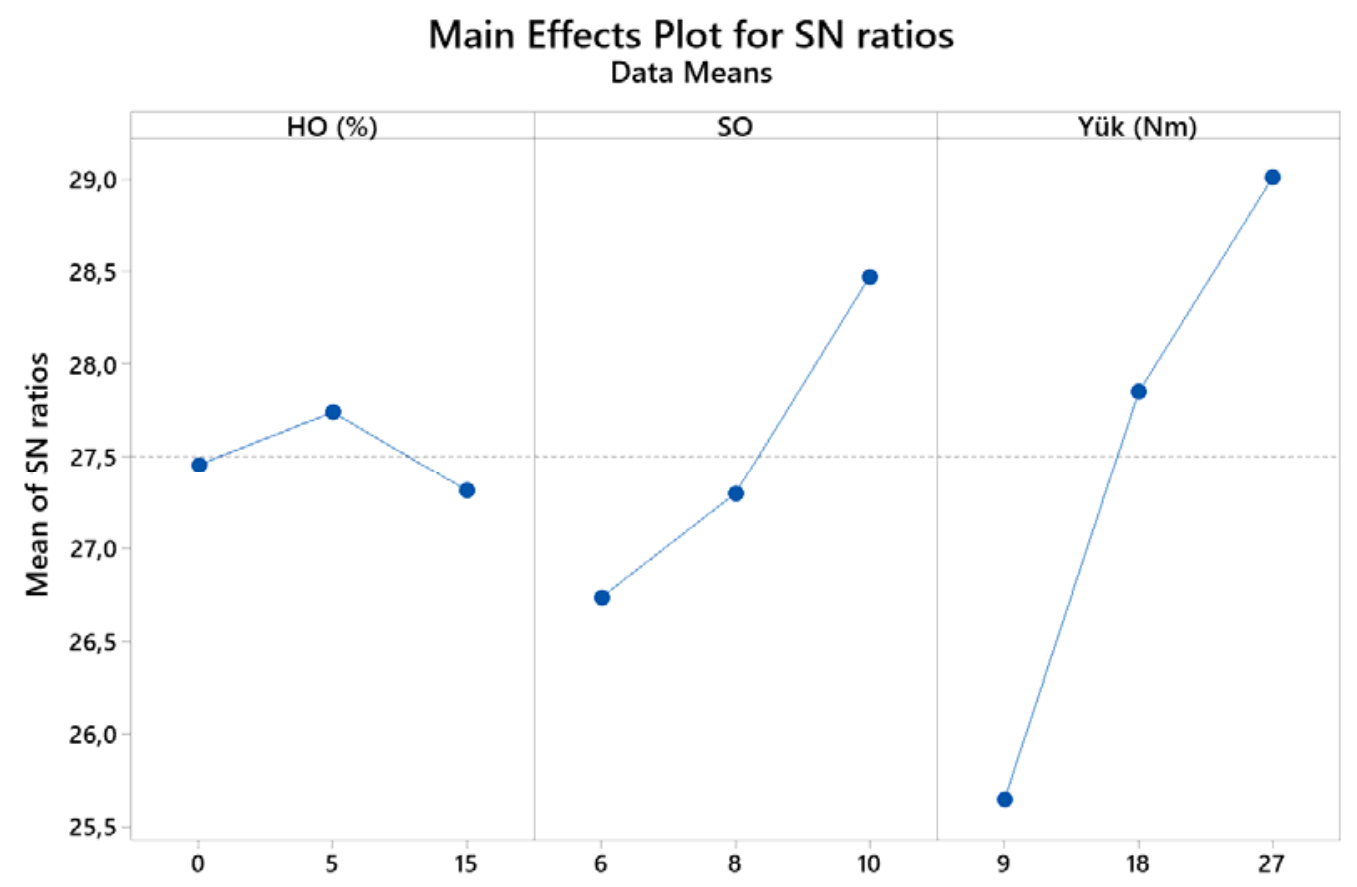

Signal-to-noise: Larger is better

Şekil 1. FEV için S/N oranları

Pareto Chart of the Standardized Effects

(response is FEV $(\%) ; \alpha=0,05$ )

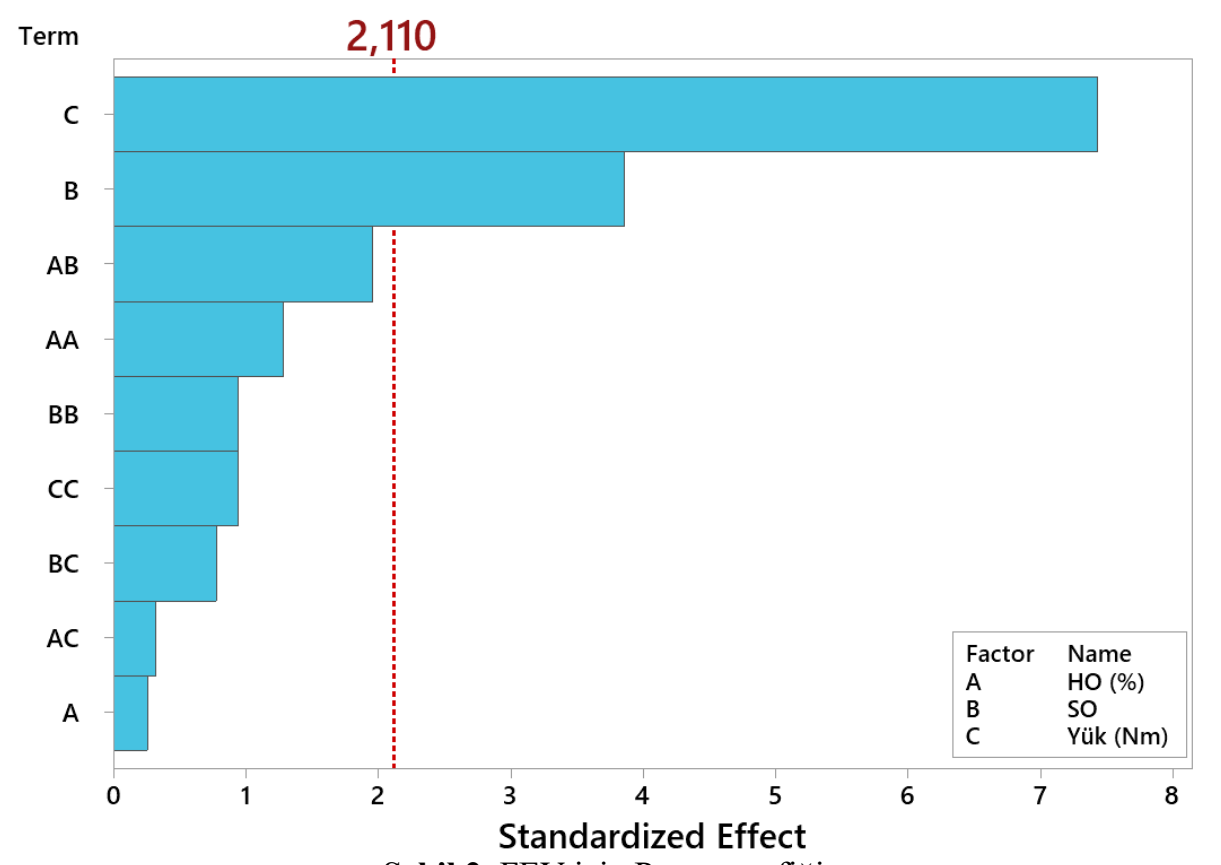

Şekil 2. FEV için Pareto grafiği

FEV $=17.9+1.198 \mathbf{H O}-2.79 \mathbf{S O}+0.655$ Yük $-0.0573 \mathbf{H O} * \quad$ HO $+0.248 \mathbf{S O} * \quad$ SO

(\%) $\quad-0.0123$ Yük * Yük -0.0986 HO * SO + 0.0074 HO * Yük + 0.0321 SO * Yük

Şekil 3 ve Şekil 4'te FÖYT için sırasıyla S/N oranları ve Pareto grafiği gösterilmektedir. S/N oranları grafiğine göre en iyi FÖYT değeri için optimum motor değişkenleri HO için \%0, SO için 10.0:1 ve yük için 27 Nm olarak tespit edilmiştir. FÖYT üzerindeki en etkin değişkenler ise SO ve yük olarak bulunmuştur. Motordan aynı çıkış gücünün alınabilmesi için alt 1sıl değeri düşük olan yakıttan daha fazla kullanılması gerekmektedir. 1-heptanol benzine kıyasla daha düşük bir alt 1sıl değere sahip olduğu için, artan HO ile birlikte FÖYT olumsuz olarak etkilenmiştir. FEV değerinde olduğu gibi, artan SO ve yük değerleri FÖYT değerini de olumlu yönde etkilemiştir ve en düşük FÖYT değerleri en yüksek SO ve yük seviyelerinde elde edilmiştir. FÖYT için elde edilen regresyon denklemi, denklem (4)’te verilmiştir. 


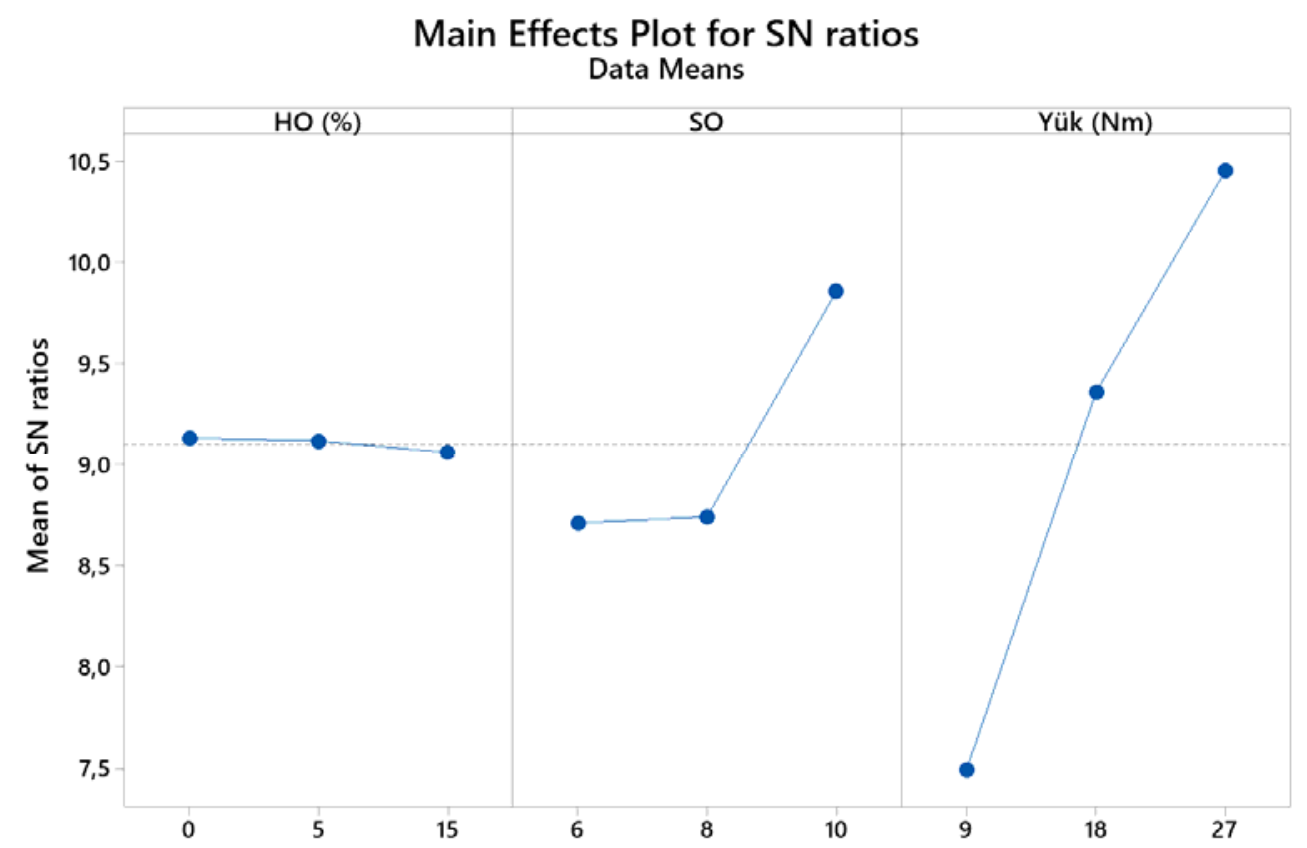

Signal-to-noise: Smaller is better

Şekil 3. FÖYT için S/N oranları

Pareto Chart of the Standardized Effects

(response is FÖYT $(\mathrm{kg} / \mathrm{kWh}) ; \alpha=0,05)$

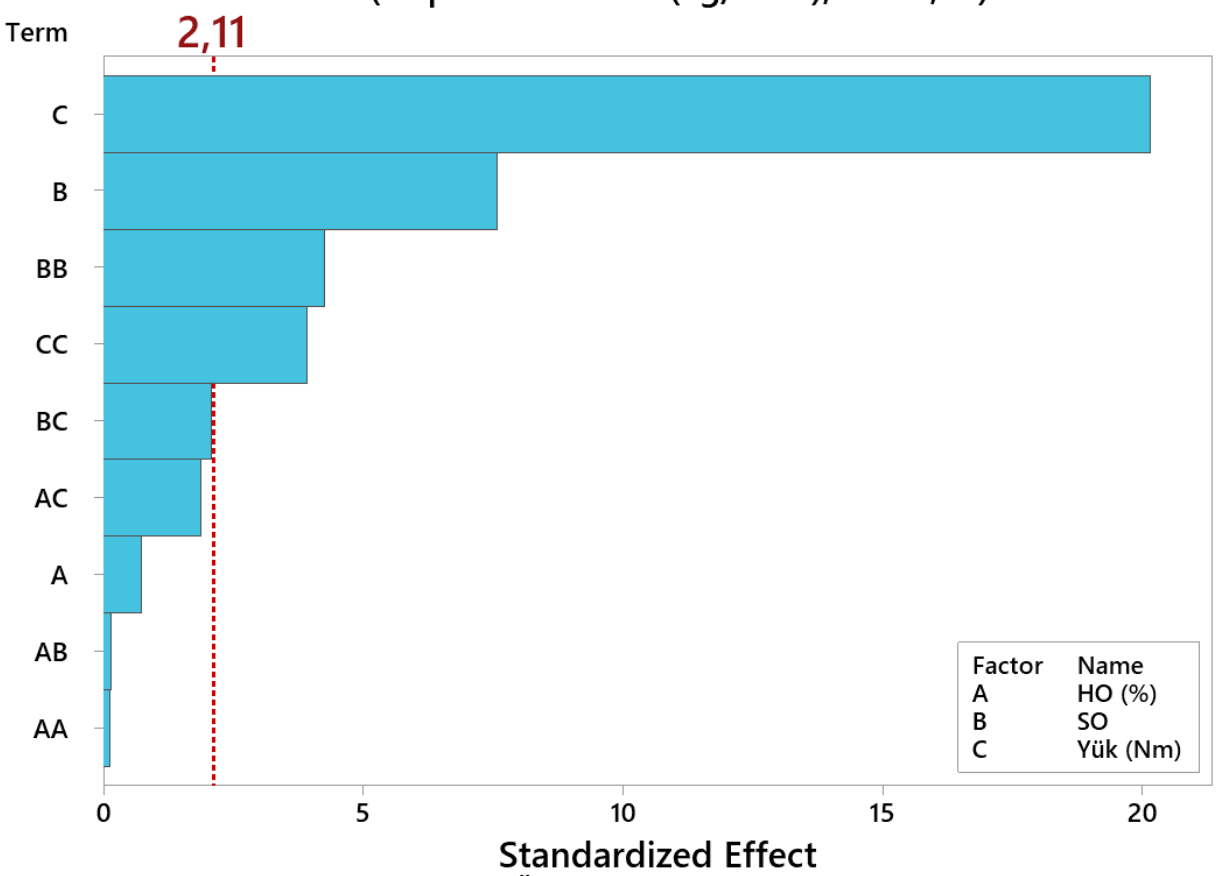

Şekil 4. FÖYT için Pareto grafiği

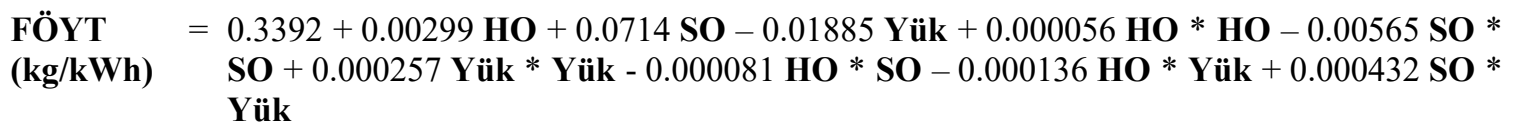

Bu çalışmadaki optimizasyonun amacı, FEV'i maksimize ederken, eş zamanlı olarak FÖYT'ü en aza indirmektir. Yukarıdaki bölümde gösterilen S/N oranları grafiklerinde her motor çıkışı için ayrı ayrı optimum sonuçlar belirlenmiş ancak bu bölümde tüm çıtılların optimizasyonu eş zamanlı olarak gerçekleştirilmiştir. Optimizasyon kriterleri Tablo 4'te verilmiştir. Bu kriterlere göre optimizasyondan elde edilen sonuçlar Şekil 5'te gösterilmiştir. Optimizasyondan elde edilen \%5 HO, 10.0:1 SO ve $27 \mathrm{Nm}$ motor yükü optimum çalışma parametrelerine istinaden ortaya çıan FEV ve FÖYT ise sirasıyla \%33.120 ve $0.278 \mathrm{~kg} / \mathrm{kWh}$ olarak bulunmuştur. Ayrıca, optimizasyonun performansını değerlendirmek amacıyla bir doğrulama çalışması yapılmıştır. Tablo 5'te gösterilen doğrulama çalışmasına göre optimizasyon sonuçları ile deney sonuçları arasındaki hata \%10'dan daha az bulunmuştur. FEV 
ve FÖYT için test ve optimizasyon sonuçlarının grafiksel kıyaslanması sırasıyla Şekil 6 ve Şekil 7'de gösterilmektedir.

Tablo 4. Optimizasyon kriterleri

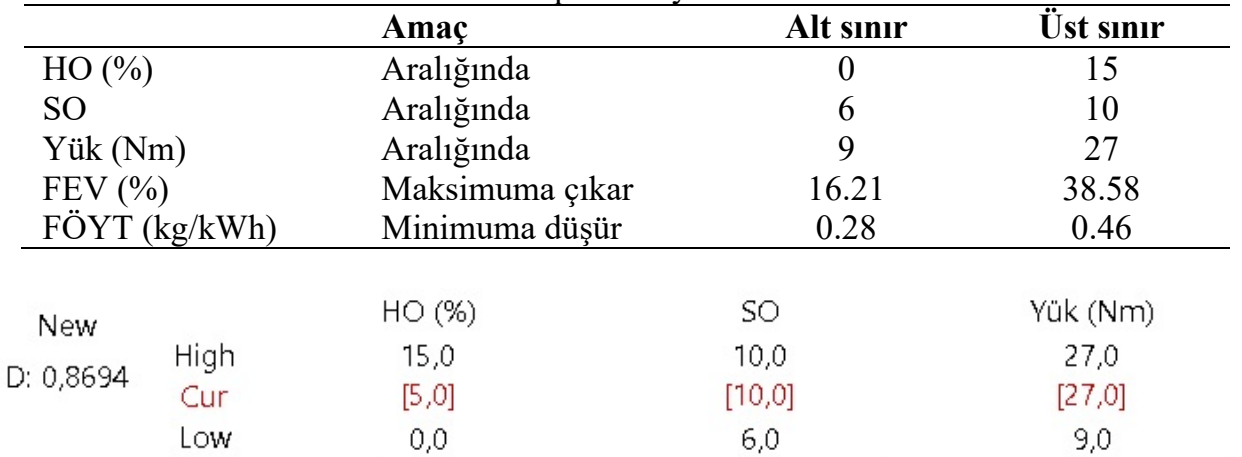

Composite

Desirability

D: 0,8694

FEV (\%)

Maximum

$y=33,1195$

$d=0,75590$

FÖYT $(\mathrm{kg}$

Minimum

$y=0,2782$

$d=1,0000$

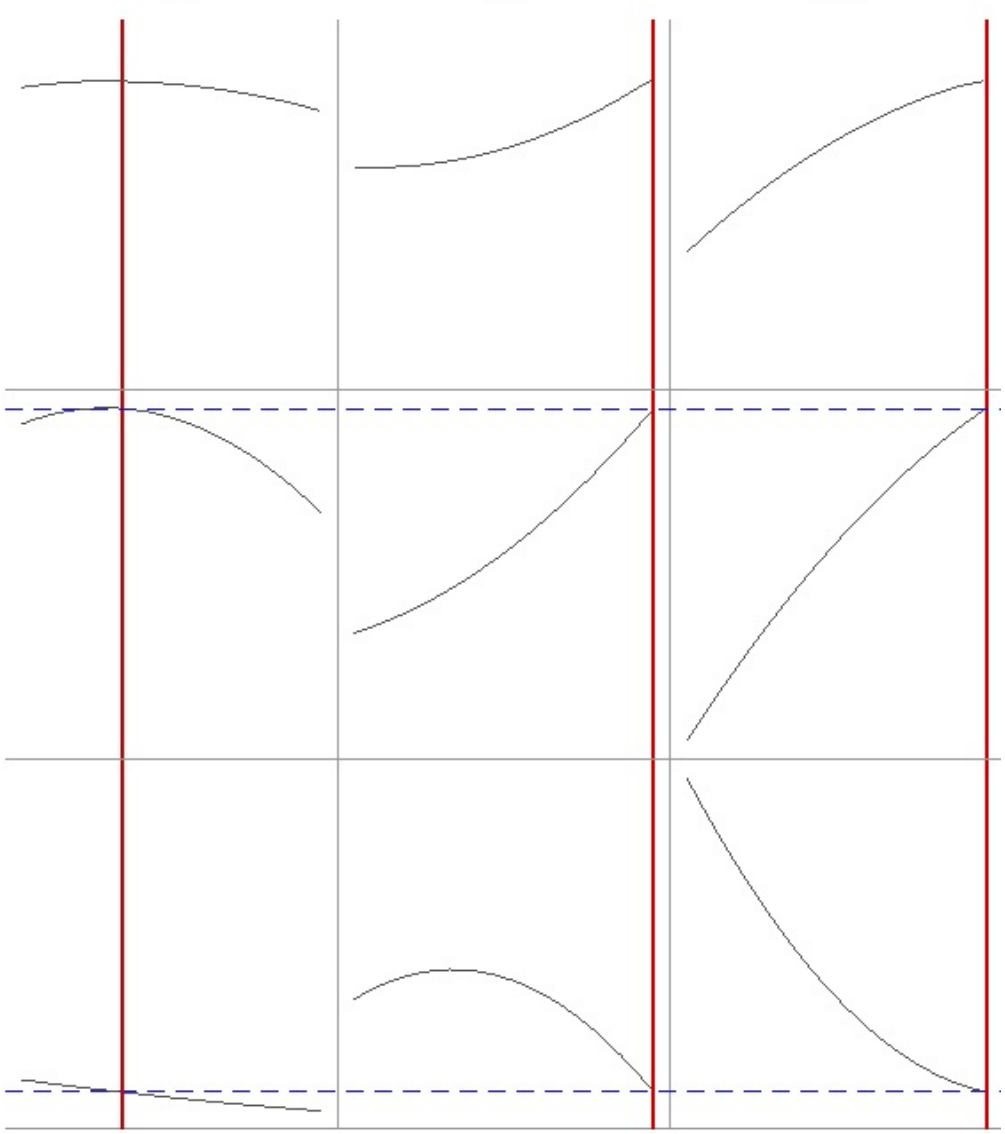

Şekil 5. Optimizasyon sonuçları

Tablo 5. Doğrulama

\begin{tabular}{cccccc}
\hline HO (\%) & SO & Yük (Nm) & Değer & $\begin{array}{c}\text { FEV } \\
(\mathbf{\%})\end{array}$ & $\begin{array}{c}\text { FÖYT } \\
(\mathbf{k g} / \mathbf{k W h})\end{array}$ \\
\hline 5 & $10.0: 1$ & 27 & Optimizasyon & 33.120 & 0.278 \\
& & & Test & 36.580 & 0.284 \\
& & & Hata $(\%)$ & 9.46 & 2.11 \\
\hline
\end{tabular}




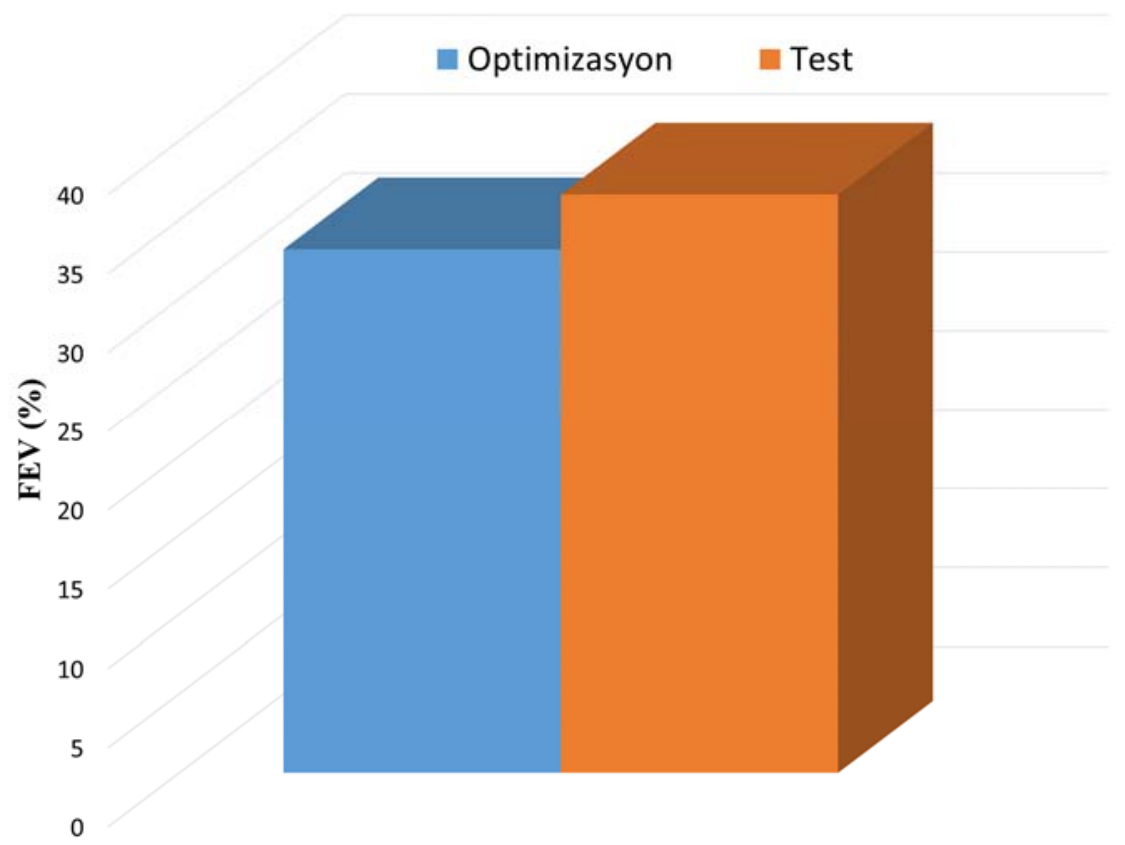

Şekil 6. FEV için optimizasyon ve test sonuçlarının grafiksel kıyaslanması

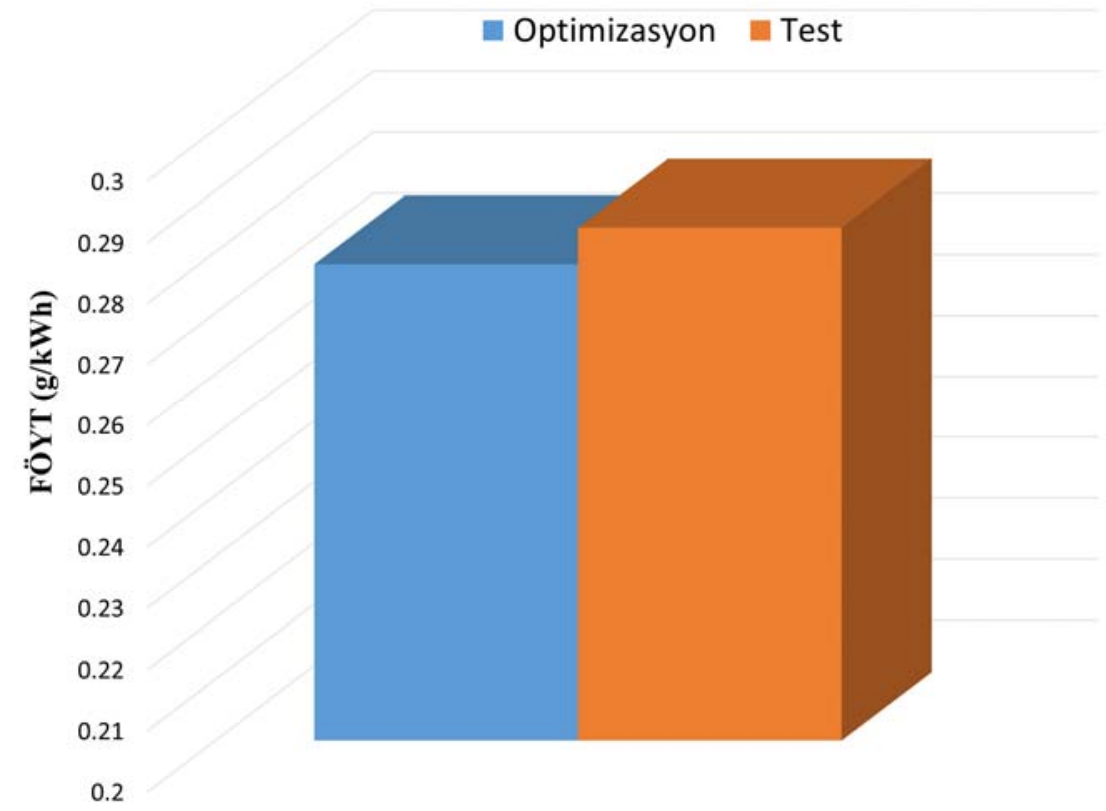

Şekil 7. FÖYT için optimizasyon ve test sonuçlarının grafiksel kıyaslanması

\section{SONUÇ}

Bu çalışmada tek silindirli buji ateşlemeli motorda çalışma parametreleri 1-heptanol oranı, sıkıştırma oranı ve motor yükü seçilerek bir iyileştirme çalışması yapılmıştır. En iyi FEV ve FÖYT değerlerini tespit etmek için optimum motor değişkenleri belirlenmiştir. Bunun için ANOVA ve Pareto grafikleri ile desteklenen Taguchi tasarım yöntemi kullanılmıştır. Elde edilen sonuçlara göre;

$\checkmark \quad \% 5 \mathrm{HO}, 10.0: 1 \mathrm{SO}$ ve $27 \mathrm{Nm}$ motor yükü optimum çalışma parametreleri olarak tespit edilmiştir.

$\checkmark$ Optimum motor değişkenlerine istinaden ortaya çıkan optimum FEV ve FÖYT ise sırasıyla \%33.120 ve $0.278 \mathrm{~kg} / \mathrm{kWh}$ olarak bulunmuştur. 
$\checkmark$ Taguchi sonuçlarını deney sonuçları ile karşılaştırmak için yapılan doğrulama çalışmasına göre FEV ve FÖYT için hata oranları sırasıyla \%9.46 ve \%2.11 olarak bulunmuştur.

$\checkmark$ Geleneksel deneysel çalışma ve Taguchi tasarımının kombinasyonu ile seçilen değişkenlerin motor üzerindeki etkilerinin hızlı ve verimli bir şekilde değerlendirilebileceği sonucuna varılmıştır.

\section{Yazar Katkıları}

Hayri Yaman ve Murat Kadir Yeşilyurt tüm deneyleri tasarlamıştır ve gerçekleştirmişlerdir. Samet Uslu sonuçları analiz etmiş ve makaleyi yazmıştır.

\section{Çıkar Çatıșması}

Makale yazarları aralarında herhangi bir çıkar çatışması olmadığını beyan ederler

\begin{tabular}{|c|c|}
\hline Kisaltmalar & \\
\hline$A N O V A$ & Varyans Analizi \\
\hline FEV & Fren Efektif Verimi \\
\hline$F \ddot{O Y T}$ & Fren Özgül Yakıt Tüketimi \\
\hline $\mathrm{HO}$ & 1-heptanol Oranı \\
\hline$i$ & Tasarım Parametresi Sayısı \\
\hline$n$ & Test Say1s1 \\
\hline SO & Sikıștırma Oranı \\
\hline$S / N$ & Sinyal-Gürültü \\
\hline$y_{i}$ & Her Bir Test Sonucu \\
\hline
\end{tabular}

\section{KAYNAKÇA}

[1] M.K. Yesilyurt "The effects of the fuel injection pressure on the performance and emission characteristics of a diesel engine fuelled with waste cooking oil biodiesel-diesel blends", Renewable Energy, vol. 132, pp. 649-666, 2019.

[2] A. Biswal, R. Kale, G.R. Teja, S. Banerjee, P. Kolhe, and S. Balusamy "An experimental and kinetic modeling study of gasoline/lemon peel oil blends for PFI engine", Fuel, vol. 267, 2020.

[3] X. Zhen, Y. Wang, and D. Liu "Bio-butanol as a new generation of clean alternative fuel for SI (spark ignition) and CI (compression ignition) engines", Renewable Energy, vol. 147, no 1, pp. 2494-2521, 2020.

[4] M. Passaponti, L. Rosi, M. Savastano, W. Giurlani, H.A. Miller, A. Lavacchi, J. Filippi, G. Zangari, F. Vizza, and M. Innocenti "Recycling of waste automobile tires: Transforming char in oxygen reduction reaction catalysts for alkaline fuel cells", Journal Of Power Sources, vol. 427, pp. 85-90, 2019.

[5] S.P. Jagtap, A.N. Pawar, and S. Lahane "Improving the usability of biodiesel blend in low heat rejection diesel engine through combustion, performance and emission analysis", Renewable Energy, vol. 155, pp. 628-644, 2020.

[6] S. Uslu, and M.B. Celik "Performance and Exhaust Emission Prediction of a SI Engine Fueled with Iamyl Alcohol-Gasoline Blends: An ANN Coupled RSM Based Optimization", Fuel, vol. 265, pp. 116922, 2020.

[7] B.G. Şanlı, E. Uludamar, and M. Özcanlı "Evaluation of energetic-exergetic and sustainability parameters of biodiesel fuels produced from palm oil and opium poppy oil as alternative fuels in diesel engines", Fuel, vol. $258,2019$.

[8] M.K. Yesilyurt "A detailed investigation on the performance, combustion, and exhaust emission characteristics of a diesel engine running on the blend of diesel fuel, biodiesel and 1-heptanol (C7 alcohol) as a next-generation higher alcohol", Fuel, vol. 275, pp. 117893, 2020.

[9] D. Leite, R.F. Santos, D. Bassegio, S.N.M. de Souza, D. Secco, F. Gurgacz, T.R.B. da Silva "Emissions and performance of a diesel engine affected by soybean, linseed, and crambe biodiesel", Industrial Crops \& Products, vol. 130, pp. 267-272, 2019.

[10] S. Uslu, and M.B. Celik "Combustion and emission characteristics of isoamyl alcohol-gasoline blends in spark ignition engine", Fuel, vol. 262, 2020.

[11] M. Zaharin, N. Abdullah, G. Najafi, H. Sharudin, and T. Yusaf "Effects of physicochemical properties of biodiesel fuel blends with alcohol on diesel engine performance and exhaust emissions: A review.", Renewable and Sustainable Energy Reviews, vol. 79, pp. 475-493, 2017.

[12] Y. Li, Y. Chen, G. Wu, C. Lee, F. Fon, and J. Liu "Experimental Comparison of Acetone-n-ButanolEthanol (ABE) and Isopropanol-n-Butanol-Ethanol (IBE) As Fuel Candidate In Spark-Ignition Engine", Applied Thermal Engineering, vol. 133, pp. 179-187, 2018. 
[13] M.A. Ratcliff, J. Luecke, A. Williams, E. Christensen, J. Yanowitz, A. Reek, and R.L. McCormick "Impact of Higher Alcohols Blended İn Gasoline On Light-Duty Vehicle Exhaust Emissions", Environmental Science And Technology, vol. 47, no. 23, pp. 13865-13872, 2013.

[14] M. Nour, A. Attia, and S. Nada "Combustion, performance and emission analysis of diesel engine fuelled by higher alcohols (butanol, octanol and heptanol)/diesel blends", Energy Conversion And Management, vol. 185, pp. 313-329, 2019.

[15] S. Mani Sarathy, S. Park, B.W. Weber, W. Wang, P.S. Veloo, A.C. Davis, C. Togbe, C.K. Westbrook, O. Park, G. Dayma, Z. Luo, M.A. Oehlschlaeger, F.N. Egolfopoulos, T. Lu, W.J. Pitz, C.J. Sung, and P. Dagaut "A comprehensive experimental and modeling study of iso-pentanol combustion", Combustion and Flame, vol. 160, np. 12, pp. 27122728, 2013.

[16] A.I. EL-Seesy, H. Kosaka, H. Hassan, and S. Sato "Combustion and emission characteristics of a common rail diesel engine and RCEM fueled by nheptanol-diesel blends and carbon nanomaterial additives", Energy Conversion And Management, vol. 196, pp. 370-394, 2019.

[17] M. K. Yesilyurt "The examination of a compressionignition engine powered by peanut oil biodiesel and diesel fuel in terms of energetic and exergetic performance parameters", Fuel, vol. 278, pp. 118319 , 2020.

[18] S. Uslu "Optimization of diesel engine operating parameters fueled with palm oil-diesel blend: Comparative evaluation between response surface methodology (RSM) and artificial neural network (ANN)", Fuel, vol. 276, pp. 117990, 2020.
[19] Y. Singh, A. Sharma, G.K. Singh, A. Singla, and N.K. Singh "Optimization of performance and emission parameters of direct injection diesel engine fuelled with pongamia methyl esters-response surface methodology approach", Industrial Crops \& Products, vol. 126, pp. 218-226, 2018.

[20] S. Uslu, and M. Aydın "Effect of operating parameters on performance and emissions of a diesel engine fueled with ternary blends of palm oil biodiesel/diethyl ether/diesel by Taguchi method", Fuel, vol. 275, pp. 117978, 2020.

[21] N.A. Ansari, A. Sharma, and Y. Singh "Performance and emission analysis of a diesel engine implementing polanga biodiesel and optimization using Taguchi method", Process Safety And Environmental Protection, vol. 120, pp. 146-154, 2018.

[22] M.K. Balki, C. Sayin, and M. Sarıkaya "Optimization of the operating parameters based on Taguchi method in an SI engine used pure gasoline, ethanol and methanol", Fuel, vol. 180, pp. 630-637, 2016.

[23] S.P. Jena, S. Mahapatra, and S.K. Acharya, "Optimization of performance and emission characteristics of a diesel engine fueled with Karanja biodiesel using Grey-Taguchi method", Materials Today: Proceedings, 2020.

[24] R.K. Rai, and R.R. Sahoo, "Taguchi-Grey method optimization of VCR engine performance and heat losses by using Shorea robusta biodiesel fuel", Fuel, vol. 281, pp. 118399, 2020.

[25] P.K. Bose, M. Deb, R. Banerjee, and A. Majumder "Multi objective optimization of performance parameters of a single cylinder diesel engine running with hydrogen using a Taguchi-fuzzy based approach", Energy, vol. 63, pp. 375-386, 2013. 